\title{
Letters
}

Website: bmj.com

Email: letters@bmj.com

\section{Measles, mumps, and rubella (MMR) vaccine and autism}

\section{Ecological studies cannot answer main question}

EDITOR-Kaye et al undertook an ecological study comparing the time trend in measles, mumps, and rubella (MMR) vaccine coverage with the time trend in diagnoses of autism. ${ }^{1}$ They found a marked increase in the incidence of codes for autism in children's electronic general practice records over 11 years.

We agree with their conclusion that MMR cannot be the cause of this observed increase since the vaccine coverage remained constant over the same time. There have been changes in the classification of autistic diseases and in the likelihood of case ascertainment in recent years, and a more rigorous review of cases may clarify whether some of the increase was due to alterations in diagnostic practice. ${ }^{2}$ Only $81 \%$ of cases were reported to have been referred to a specialist, raising questions about the validity of the diagnoses used by Kaye et al. Children with medical conditions present from birth and known to be associated with an increased risk of autism (fragile $\mathrm{X}$ disorder, tuberous sclerosis, phenylketonuria, and congenital rubella) were not excluded.

The failure to find an association between the time trends in vaccine coverage and the incidence of autism codes in children's electronic general practice records does not exclude a causal association. Whether exposure to MMR vaccination increases the risk of autism is of great public health importance and can be usefully investigated using the general practice research database. We have been funded by the United Kingdom Medical Research Council to undertake an investigation of the causes of autism, including an assessment of the potential role of MMR vaccine using case-control and case series approaches. The electronic general practice records in the database will be supplemented by a full record review of all cases and, subject to ethical approval, questionnaires to parents of both affected children and controls. We will undertake a detailed validation and classification of all cases and establish the date of onset of symptoms. In addition, we will obtain information on potential confounding factors from both cases and controls. A detailed protocol of our study has been published. ${ }^{3}$
Liam Smeeth clinical research fellow, department of epidemiology and population health liam.smeeth@lshtm.ac.uk

Andrew J Hall head, infectious disease epidemiology unit

Laura C Rodrigues reader in epidemiology,

department of infectious and tropical diseases

Xiangning Huang research fellow, department of infectious and tropical diseases

Peter G Smith head, department of infectious and tropical diseases

London School of Hygiene and Tropical Medicine, London WC1E 7HT

Eric Fombonne reader in epidemiological child

psychiatry

Institute of Psychiatry, King's College London, Department of Child and Adolescent Psychiatry, Medical Research Council Child Psychiatry Unit, London SE5 8AF

1 Kaye JA, del Mar Melero-Montes M. Mumps, measles, an rubella vaccine and the incidence of autism recorded by general practitioners: a time trend analysis. $B M J$ 2001;322:460-3. (24 February.)

2 Fombonne E. Is there an epidemic of autism? Pediatrics 2001;107:411-3.

3 Smeeth L, Hall AJ, Fombonne E, Rodrigues LC, Huang X, Smith PG. A case-control study of autism and mumpsmeasles-rubella vaccination using the general practice measles-rubella vaccination using the general practice
research database: design and methodology. BMC Public research datab $2001: 1: 2$.

\section{Argument is too simplistic}

EDITOR-Kaye et al analysed time trends in measles, mumps, and rubella (MMR) vaccine and the incidence of autism. ${ }^{1}$ Because the increase of autism is gradual whereas the prevalence of immunisation is constant, they argue that there is no evidence of an association. This argument, however, rests on the assumption that the rate of diagnosis rate each year after the onset of clinical symptoms is constant with respect to birth cohort and that a mild case has a constant chance of being diagnosed.

Altmann points out that $40 \%$ of cases have diagnosis delayed up to three years. ${ }^{2}$ Could increasing awareness of paediatricians and general clinicians of autism during this period account for the gradual increase? When the first unexpected extra cases were found in 1991-2, could that not have increased vigilance? As evidence, we point to the median age at diagnosis as reported by the authors. Except for 1993, there seems to be a trend towards earlier diagnosis. We exclude 1998-9 because the cohort then changed substantially, with several practices no longer providing information. Could Kaye et al show a test of trend from 1988 to 1997 to see whether there was a systematic decrease in age at diagnosis? Is it also possible to investigate the notion that average severity of cases was dropping over this time period?
Finally, was there a trend towards earlier vaccination, as can be seen in data from California?? ${ }^{3}$ For example, did the percentage of vaccinations at less than 10 months increase over time?

We submit that the argument given by Kaye et al is too simplistic to reassure us that there is no link between MMR and autism. The current arguments in favour of the link, however, remain unconvincing. ${ }^{4}{ }^{5}$

Michael Edwardes research fellow

Division of Clinical Epidemiology, Ross 4.06, Roya Victoria Hospital, 687 Pine Avenue West, Montreal, Province of Quebec, Canada H3A 1A1

michael.edwardes@clinepi.mcgill.ca

Marc Baltzan consultant physician

Mount-Sinai Hospital, 5690 Cavendish, Cote-St-Luc, Montreal, Province of Quebec, Canada H4W 1S7

1 Kaye JA, del Mar Melero-Montes M. Mumps, measles, and rubella vaccine and the incidence of autism recorded by general practitioners: a time trend analysis. BMJ 2001;322:460-3. (24 February.)

2 Altmann D. Autism and measles, mumps and rubella vaccine. Lancet 2000;355:409.

3 Dales L, Hammer SJ, Smith NJ. Time trends in autism and in MMR immunization coverage in California. JAMA 2001;285:1183-5.

4 Wakefield AJ, Murch SH, Anthony A, Linell J, Casson DM, Malik M, et al. Ileal-lymphoid-nodular hyperplasia, non-specific colitis and pervasive developmental disorder in children. Lancet 1998:351:637-41.

5 Wakefield AJ. MMR vaccination and autism. Lancet 1999:354:949-50.

\section{MMR cannot be exonerated without} explaining increased incidence of autism EDITOR-Kaye et al observe that the rise in the incidence of autism cannot be attributed to measles, mumps, and rubella (MMR) vaccine because vaccination remained consistently above $90 \%$ in the period studied.

I have several issues with their study:

(1) The cohort of children chosen was born during 1988-93. MMR was introduced in the United Kingdom in 1988 and an uptake of $90-95 \%$ is unlikely to have been achieved from the first year.

(2) Kaye et al effectively excluded children born before 1988 who may have been vaccinated in or after 1988 .

(3) The 114 boys selected were observed until the age of 71 months. Many of them could have succumbed after the second MMR vaccination (booster), which is given between the ages of 4 and 5 years. The study did not mention how many children received two MMR vaccinations.

(4) MMR vaccine was previously given alone at 15 months or later. Then the age was lowered to 12-14 months and other vaccines were administered concomitantly, increasing the immune antigenic insult at a younger more susceptible age and effectively increasing the incidence of autism. 
(5) The restriction of the cases in the main analysis to 114 boys is of concern. A breakdown of the 290 children in the 1990-9 birth cohorts by sex and year of birth would have been informative. A larger proportion of girls among the 176 cases excluded might have been relevant to the completeness of the autism figures.

(6) The fact that neither DSM-IV nor IC-10 was systematically used in the United Kingdom creates further doubts about the significance of the findings.

Professor Brent Taylor in the Lancet (1999;353:2026-9) and now Kaye et al have clearly documented the epidemic of autism in the United Kingdom. Before 1988 the incidence of autism was 1 in 10000 ; after 1988-the year MMR was introduced-it leapt to 8 in 10000 . By 1993 it was 29 in 10000 .

Kaye et al cannot exonerate MMR without offering a reasonable explanation for the increase.

Until safety studies on MMR are independent of drug companies and are large scale and comprehensive, and until researchers review with parents the documented adverse reactions of bowel disease and autism, the triple jab remains suspect.

F Edward Yazbak doctor

TL Autism Research, 70 Viewcrest Drive, Falmouth, MA 02540, USA

1 Kaye JA, del Mar Melero-Montes M. Mumps, measles, and rubella vaccine and the incidence of autism recorded by general practitioners: a time trend analysis. $B M$ J 2001;322:460-3. (24 February)

\section{Authors' reply}

EDITOR-We disagree with Smeeth et al applying the term ecological to our study of measles, mumps, and rubella (MMR) vaccine and autism. In an ecological study the units of analysis are populations or groups of people. ${ }^{1}$ But our study focused on individual children diagnosed with autism (although we also reported the prevalence of exposure to MMR for all children in the general practice research database who were born in 1988-93). It is unimportant that we included a few children with conditions predisposing to autism because we were evaluating the relation between MMR vaccination and the risk of being diagnosed with autism per se. We agree that more work is needed to evaluate possible causes of the recent increase in autism other than the MMR vaccine.

A non-parametric test (extension of Wilcoxon rank sum test in Stata, version 7.0) provides no evidence for a trend toward lower age at diagnosis over time for the 305 cases diagnosed in 1988-99 $(\mathrm{P}=0.88)$, even including only cases diagnosed before 1998 $(p=0.61)$. We doubt that lower age at diagnosis explains the nearly fourfold increase in risk for two to five year olds in the 1988-93 birth cohorts. The median age at first MMR in the base population was 15 months for the 1988 birth cohort, 14 months for the 1989-1996 cohorts, and 13 months for the 1997 cohort. Small differences in age at first MMR are unlikely to account for the large change in the observed risk of autism diagnosed at age 2-5. We agree that changing diagnostic criteria (for example, diagnosing milder cases) may be one explanation for the increase in diagnosed autism.

We did not include only classic cases. We restricted our main analysis to boys to maximise risk estimate precision since girls make up only about a fifth of the diagnosed cases. We focused on children aged 2-5, in whom the incidence of diagnosed autism is greatest. We analysed 1988-93 birth cohorts to have enough follow up information to calculate four year risk (age 2-5). Using a different upper limit for age at diagnosis in some birth cohorts would impair the comparability of risk among the cohorts.

MMR was introduced in the United Kingdom in 1988 and is first administered around the age of 15 months. Children born in 1988 were vaccinated in 1989 or 1990 , so our data do not suggest that uptake of $95 \%$ was achieved from the first year. Excluding cases born before 1988 has no effect on risk estimates for the birth cohorts we reported or on the relation between MMR vaccine and diagnosed autism in these cohorts. Only $12 / 114$ boys in our main analysis received more than one MMR vaccination before their first recorded diagnosis of autism- too few to separately estimate risk for two vaccinations compared with one. We did not study whether vaccines other than MMR are associated with the increasing incidence of autism.

James A Kaye epidemiologist

Maria del Mar Melero-Montes epidemiologist Hershel Jick associate professor of medicine Boston Collaborative Drug Surveillance Program Boston University School of Medicine, 11 Muzzey Street, Lexington, MA 02421, USA

A longer version of this letter is published on bmj.com

1 Last JM, ed. A dictionary of epidemiology. 4th ed. New York: Oxford University Press, 2001.

\section{Asthma and early childhood infectious disease}

\section{Infection is trigger rather than cause}

EDITOR-The study by Illi et al is suggestive of a protective role of early upper respiratory tract infections against the development of asthma later in life. ${ }^{1}$ Concerning lower respiratory tract infections, a positive association with the development of asthma has been proposed. But as these infections were found to be significantly higher in children with a family history of atopy, Illi et al conclude that they rather represent manifestations of children already predisposed to asthma.

We analysed the preliminary results of a prospective study of infants with bronchiolitis during the first year of life. We enrolled all the 238 infants admitted to two major paediatric departments in Crete from January 1999 to April 2000. The infants were classified as positive or negative for respiratory syncytial virus from the results of a rapid test for respiratory syncytial virus antigen in nasopharyngeal secretions (Abbott Test Pack RSV rapid diagnostic kit). The outcome was evaluated on the basis of annual parental interview. Criteria for classification in the severe recurrent wheezing group included the need for asthma prophylaxis regimens or for admission because of respiratory distress. Among the 133 children who completed their first year of follow-up, the positive group $(n=71)$ did not show any predisposition to develop severe recurrent wheezing. Remarkably, infants negative for respiratory syncytial virus $(\mathrm{n}=62)$ seemed to be more prone to severe recurrent wheezing than positive infants $\left(\chi^{2}\right.$ test, $\mathrm{P}=0.058$; relative risk 1.51 (95\% confidence interval 0.975 to 2.34$)$ ). Positive family history was significantly more frequent in the infants who developed severe wheezing than in those with mild or no wheezing episodes $\left(\chi^{2}\right.$ test, $\left.\mathrm{P}<0.01\right)$.

The relation of respiratory syncytial virus infection in early life to the later development of asthma has not yet been defined. Both studies indicating respiratory syncytial virus as a risk factor predisposing to asthma through allergic sensitisation, and studies that implicate the virus as responsible for the development of asthma without increasing the risk for allergy have been published. ${ }^{23}$ In our study respiratory syncytial virus infection seems unrelated to subsequent development of severe recurrent wheezing in the following year. In agreement with the findings of Illi et al, our findings indicate that severe wheezing in early life occurs more often in predisposed children, and infection is a trigger rather than a cause.

Vassiliki Angelakou consultant in paediatrics Maria Bitsori specialist registrar in paediatric. Emmanouil Galanakis assistant professor of paediatrics

Department of Paediatrics, Venizelion and Pananion General Hospital of Heraklion, POB 44, Gr-71 001 Heraklion, Crete, Greece

1 Illi S, von Mutius E, Lau S, Bergmann R, Niggeman B, Sommerfeld C, et al. Early childhood infectious diseases and the development of asthma at school age: a birth cohort study. BMJ 2001;322:390-5. (17 February.)

2 Sigurs N, Bjarnason R, Sigurbergsson F, Kjellman B. Respiratory syncytial virus bronchiolitis in infancy is important risk factor for asthme and allering at ancy is an important risk factor for asthis and

3 Stein RT, Sherrill D, Morgan WJ, Holberg CJ, Halonen M, Taussig LM, et al. Respiratory syncytial virus in early life and the risk of wheeze by age 13 years. Lance 1999:354:541-5.

Critical time for protective effect of large family on asthma may not be during first year of life

EDITOR-The paper by Illi et al is in agreement with our prospective study in finding that a report of lower respiratory tract infections in the first year of life is associated with an increased risk of asthma at 7 years of age. $^{12}$ In our prospective study of 863 children followed up from birth to 7 years of age we also found that a history of a cold (upper respiratory tract infection) documented by home interview at one month was also associated with an increased risk of asthma at 7 years of age (adjusted relative risk 1.27 (95\% confidence interval 1.05 to 1.53$))$.

Like the report of runny nose episodes by Illi et al, our outcome was determined by parental report. However, we examined the construct validity of our report on upper respiratory tract infection and found this infection to be positively associated with winter, resident density, maternal smoking, 
and bottle feeding, suggesting that this report was likely to reflect early upper respiratory tract infection. As Illi et al point out, events in early life have been postulated to be particularly relevant to the subsequent development of atopic disease. Thus our data are not consistent with the concept that viral infection at a critical period in very early life will protect against the subsequent development of asthma.

In the same study we found that the apparent protective effect of larger family size on asthma seemed to be operative at age 7 but not at 1 month and that children with no siblings were more likely to have asthma with an age of onset after 4 years but not earlier. This suggests that the critical time for the protective effect of a large household on asthma is not necessarily during the first year of life.

Anne-Louise Ponsonby senior fellow

National Centre for Epidemiology and Population Health, Australian National University, Canberra ACT, Australia 0200

Andrew Kemp head

Department Immunology, Royal Childrens

Hospital, Parkville, Melbourne, Australia 3052

1 Illi S, von Mutius E, Lau S, Bergmann R, Niggeman B, Sommerfeld C, et al. Early childhood infectious disease and the development of asthma at school age: a birth cohort study. BMJ 2001;322:390-5. (17 February.)

2 Ponsonby AL, Couper D, Dwver T, Carmichael A, Kemp A. Relationship between early life respiratory illness, family size over time, and the development of asthma and hay size ove a timen and follow up study. Thorax 1999;54:661-9.

\section{Using clinical evidence}

\section{Randomised controlled trials are not the} only evidence

EDITOR-Randomised controlled trials-the focus of evidence based medicine-will be given more momentum by the availability of Clinical Evidence on line. ${ }^{1}$ The criteria to be used to select evidence for this journal imply that only recommendations from randomised controlled trials can be used if medicine is to be considered evidence based.

I urge the BMJ and Clinical Evidence to take a less conservative position on what can be regarded as clinical evidence. The exclusion from publication of anything other than randomised controlled trials (except where these do not exist on a particular topic) will dissuade clinicians and research workers from considering quantitative statistical analysis of sequential data from individuals as an alternative but meaningful form of clinical evidence. Statistical analyses of sequences of numerical data from individuals can provide evidence that is as robust and as statistically valid as data from the best randomised controlled trials.

The probability of a real effect from an intervention on an individual may be high when there are sufficient data points for analysis before and after the intervention. Interventions used may be a drug, a placebo, a physical treatment (for example, physiotherapy), the introduction of a "natural" therapy, or any other intervention when the effect can be determined by its impact on relevant numerical variables that are col- lected sequentially. The variables may be laboratory measurements, clinical measurements, or patient assessments (for example, pain scores). Reports that contain statistically valid calculations of change as a result of an intervention in an individual or in a group should have as much right to inclusion in Clinical Evidence as evidence from randomised controlled trials.

The statistical analysis of sequential information from individuals has the potential to improve clinical care for those individuals as well as providing clinica evidence for future practice. With colleagues, including clinicians and statisticians, I reported on real time monitoring applied to sequential kidney function testing in patients with renal disease $\mathrm{e}^{2.3}$ and proposed its general application in both research and clinical practice. ${ }^{4}$ That has not happened.

With its influence, Clinical Evidence could encourage the use of evidence acquired from individuals with time series analysis. This is currently used extensively for quality control in laboratories, by investors in the stock market, and by biometricians, but it is not used as it could be to provide clinical evidence, both in clinics and as a research tool.

Martin S Knapp locum consultant physician 12 Townsend Street, Ivanhoe, 3079, Australia mknapp@optushome.com.au

1 Barton S. Using clinical evidence. BMJ 2001;322;503-4 (3 March.)

2 Knapp MS, Smith AFM, Trimble IM, Pownall R, Gordon K. Mathematical and statistical aids to evaluate data from renal patients. Kidney Int 1983;24:474-86

3 Trimble IM, West M, Knapp S, Pownall R, Smith AFM. Detection of renal allograft rejection by computer. $B M$ J $1983 ; 286: 1695-9$

Knapp MS. Computing, mathematics and the nephrologist. Kidney Int 1983:24:433-5.

\section{Clinical Evidence is one of respondents} three favourite sources of information

EDITOR-We agree with Barton that presenting good quality information alone is often insufficient to change practice. ${ }^{1}$ Because we were impressed by the content, Clinical Evidence was purchased for all consultants and general practitioners (and some pharmacists) in Northumberland and Gateshead and South Tyneside Health Authorities for a year. We undertook a survey to assess how useful it had been in clinical practice; the response was 58\% (187/323) in Northumberland and 40\% (202/504) in Gateshead and South Tyneside.

The table shows that the British National Formulary was the most frequently cited favourite source of information, but 95 (24\%) respondents identified Clinical Evidence as one of their three favourite sources. Frequency of use of the book was reported as daily by four respondents, weekly by 109 , monthly by 167 , and less than monthly by 109. Most (230) used it during or after a consultation.

The publication was rated as particularly useful by general practitioners, physicians, and pharmacists; surgical specialties generally gave it a lower rating. The few people who thought that it was of no use mostly did so because the subject material was not relevant to their work. Multiple format presentations were of interest to 249 respondents, although
Favourite sources of information. Values are numbers of people citing source among their top three choices

\begin{tabular}{lc} 
Source & Frequency cited \\
\hline British National Formulary & 242 \\
\hline Journals & 152 \\
\hline Published guidelines & 101 \\
\hline Colleagues & 99 \\
\hline Clinical Evidence & 95 \\
\hline Textbooks & 61 \\
\hline Medline/Embase & 61 \\
\hline Meetings & 60 \\
\hline Internet sources & 35 \\
\hline Monthly Index of Medical Specialties & 28 \\
\hline College publications & 26 \\
\hline Cochrane database & 20 \\
\hline Library services & 17 \\
\hline Drug representatives & 7 \\
\hline National Electronic Library for Health & 3 \\
\hline
\end{tabular}

the preferred format for most (237) was the book, with 62 wanting only a paper format. Only 17 had tried the online version.

Locally we have decided to continue with a print subscription for some clinicians to complement the online access and print editions issued through the NHS. Although we cannot show that the publication has had a positive impact on clinical care, we at least show that some people are reading it. Most use related to time around the consultation, which indicates a potential link between an episode of clinical care and a desire to check the evidence. We view this as a positive development.

Sue Gordon consultant in public health medicine Department of Public Health, Northumberland Health Authority, Morpeth, Northumberland NE61 2DL

sue.gordon@dial.pipex.com

Mark Lambert consultant in public health medicine Department of Public Health, Gateshead and South Tyneside Health Authority, South Shields, Tyne and Wear NE33 3DP

1 Barton S. Using clinical evidence. BMJ 2001;322:503-4 (3 March.)

\section{Obstetricians seem to be overstating the evidence in major placenta praevia}

EDITOR-Barton is correct in saying that the pressures of clinical medicine mean that the incorporation of evidence based practice into everyday clinical practice has become almost impossible. ${ }^{1}$ This makes busy clinicians vulnerable to expert committees that purport to produce evidenced based guidelines for them.

We were recently dismayed by a guideline on the diagnosis and management of placenta praevia published by the Royal College of Obstetricians and Gynaecologists. ${ }^{2}$ The authors state, among other recommendations, that women with major placenta praevia should be managed as inpatients in the third trimester. The evidence for this was one small randomised controlled trial, which was underpowered but showed no difference between women managed as outpatients and those managed as inpatients, and a series of retrospective reviews that showed no difference in clinical outcome. The authors base their recommendation on the belief that 
Responses to questionnaire sent to obstetric units to survey antenatal management of asymptomatic placenta praevia

\begin{tabular}{lcc}
$\begin{array}{l}\text { Response to } \\
\text { questionnaire }\end{array}$ & $\begin{array}{c}\text { Minor placenta } \\
\text { praevia }\end{array}$ & $\begin{array}{c}\text { Major } \\
\text { placenta } \\
\text { praevia }\end{array}$ \\
\hline Do not know & 3 & 3 \\
\hline $\begin{array}{l}\text { No elective admission } \\
\text { offered }\end{array}$ & 130 & 63 \\
\hline $\begin{array}{l}\text { Admission in third } \\
\text { trimester }\end{array}$ & 16 & 83 \\
\hline $\begin{array}{l}\text { Mean gestation (range) } \\
\text { on admission (weeks) }\end{array}$ & 34.8 (32-38) & $34.5(28-38)$ \\
\hline
\end{tabular}

inpatient care is the current standard management.

We sent questionnaires to the 220 clinical tutors of the Royal College of Obstetricians and Gynaecologists in England and Wales to survey the antenatal management of asymptomatic placenta praevia. Altogether we received 149 responses (response rate $68 \%$ ). Eighty five obstetric units had a guideline for management of placenta praevia and 59 did not; seven were not sure. The table summarises the results.

Our practice at this hospital has been not to admit women routinely with asymptomatic major placenta praevia; this practice seems to be shared by $42 \%$ of other maternity units. Elective admission from 34.5 weeks' gestation represents a huge investment by the NHS for an unproved intervention. We hope that Clinical Evidence, which we understand is produced by the NHS, will not overstate its remit of just presenting the evidence for what does and does not work in health care.

S Ghaem-Maghami specialist registrar

Ming Li Khong medical student

Shoreh Beski specialist registrar

Zoë Penn consultant

grabahug@dircon.co.uk

Maternity Unit, Chelsea and Westminster Hospital, London SW10 9NH

1 Barton S. Using clinical evidence. BMJ 2001;322: 503-4. (3 March.)

2 Royal College of Obstetricians and Gynaecologists. Placenta praevia: diagnosis and management. London: RCOG, 2000. (Green-top guideline No 27.)

\section{Reply from editor of Clinical Evidence}

EDITOR-Knapp is right in arguing that randomised controlled trials are not the only form of good evidence. Clinical Evidence includes evidence that doesn't come from randomised controlled trials when such trials are not feasible or are unethical, and when confirmation is needed that the effects seen in randomised controlled trials ("efficacy") are deliverable in the real world ("effectiveness").

The typical problem with observational studies is not their ability to detect significant changes, it is their difficulty in excluding systematic biases that could also explain those changes. Randomised controlled trials rarely provide all the evidence needed to answer clinical questions. Few randomised controlled trials are designed to provide good evidence about harms, and good quality observational studies are likely to remain essential in any thorough review of the adverse effects of treatments.
I am encouraged by the early evaluation by Gordon and Lambert, particularly the proportion of doctors who said that they used the book during or soon after a consultation. The next steps are to ensure that Clinical Evidence covers most questions being asked by people who turn to it, and that the evidence is provided in the most useful form.

Ghaem-Maghami et al indicate their dismay with a stipulation made by a guideline. Their reaction reinforces the approach taken in Clinical Evidence-to avoid making recommendations. Instead, evidence about the effects (benefits and harms) of treatments is presented in a clear way, so that it can be weighed by all those involved (the person with the problem and his or her advisers) at the appropriate time.

Clinical Evidence is not produced by the NHS. It was first suggested by Tom Mann (who worked for the NHS), but the authors are drawn from around the world, and Clinical Evidence is published independently by the BMJ Publishing Group. The NHS plays a major part, making Clinical Evidence available to carers and by supporting high quality research and systematic reviews (for example, by the Cochrane Collaboration and the NHS Centre for Reviews and Dissemination), which underpin Clinical Evidence.

Stuart Barton editor, Clinical Evidence BMJ Publishing Group, London WC1H 9JR sbarton@bmjgroup.com

\section{Code of conduct is needed for publishing raw data}

EDITOR-Hutchon in his article showed the benefits of publishing raw data on line. ${ }^{1}$ The method of opening up raw data for research has strong parallels to the "open source" movement of the software industry, where developers freely distribute the source code and allow usage and modification. ${ }^{2}$ The open source community has learnt that this rapid evolutionary process produces better software than the traditional closed model, in which only a very few programmers can see source, and everybody else must blindly use an opaque block of bits (www.opensource.org).

Publishing raw data may in a similar way enhance the speed and quality of research, as other researchers can reanalyse the data to verify results or to draw new conclusions. Preprint servers, as well as innovative e-journals, offer possibilities to share data and encourage other scholars to participate in the research process. ${ }^{2}$ The Journal of Medical Internet Research (www.jmir.org) has, from the beginning of its existence, explicitly invited authors to attach original data that could be downloaded and dynamically analysed, for example, with JAVA applets. ${ }^{3}$ Until today, however, no author has submitted a paper with raw data. Are authors perhaps afraid that other researchers analyse their data too thoroughly, "cream off," and publish interesting results, and thus preclude the publication of further papers? In open source genomics research, debates over priority, authorship, and credit for analysing data in depth have already arisen. ${ }^{45}$ If researcher A laid open the complete dataset, and researcher $\mathrm{B}$ discovers a new relation or other "publishable" results in the dataset, what rights of first publication does researcher A have? Researcher B could probably publish new discoveries with a simple reference to the open source-which may be unsatisfactory for researcher A, especially if he or she planned to do further analyses with the dataset.

We may need a more clear code of practice on this issue. In the open source software industry, everybody who amends open source code to produce more advanced software agrees that the new software must be open source again, a practice that could be analogously applied in biomedical publishing. Also, one may encourage a practice where authors who made available the original raw data (and also subsequent authors who generated more results with these data) should be invited to act as co-authors in any subsequent publications. This prospect may enhance the willingness of researchers to open their raw data in the first place.

Gunther Eysenbach editor,Journal of Medical Internet Research

Research Unit for Cybermedicine and eHealth, Department of Clinical Social Medicine, University of Heidelberg, D-69115 Heidelberg, Germany ey@yi.com

Eun-Ryoung Sa fellow

Global Health Net-Supercourse Group, University of Pittsburgh, Department of Epidemiology, School of Public Health, Pittsburgh, PA 15213, USA

1 Hutchon DJR. Infopoints: Publishing raw data and real time statistical analysis on e-journals. BMJ 2001;322:52930. (3 March.)

2 Eysenbach G. The impact of preprint servers and electronic publishing on biomedical research. Curr Opin

3 Eysenbach G. Welcome to the Journal of Medical Internet Eysenbach G. Welcome to the Journal of Medical Internet
Research. J Med Internet Res 1999;1:e5. Online available at www.jmir.org/1999/1/e5/(accessed 2 March 2001).

www.jmir.org/1999/1/e5/ (accessed 2 March 2001).
4 Russ AP, Aparicio SA, Carlton MB. Open-source work Russ AP, Aparicio SA, Carlton MB. Open-source work
even more vital to genome project than to software. Nature 2000;404:809

5 Anonymous. Debates over credit for the annotation of genomes. Nature 2000;405:719.

\section{Winter deaths: warm housing is not enough}

Editor-Olsen's article gives the impression that Britain's high winter mortality and winter crises in health care can be prevented simply by warmer housing, although one reference in it reviews evidence of the importance of outdoor cold exposure. ${ }^{12}$ Large scale international surveys have shown an independent association of outdoor, as well as indoor, cold with excess mortality in cold weather." A population of elderly people living in fully heated housing experienced similar excess winter mortality to the general elderly population. ${ }^{4}$ This is not surprising when people spend substantial time outdoors, since cold stress to people waiting at a bus stop in a cold wind can exceed anything experienced indoors.

Home heating has improved greatly over the past 30 years. Particular focus is 
now needed on exposure to the cold outdoors. Age Concern and other charities have responded by giving advice on avoidance of cold stress outdoors, but campaigns by government departments have remained fixated on indoor cold. Apart from personal measures such as warm clothing and exercise when outdoors in cold weather, there is scope for official action on physical measures such as windproof bus shelters, and in some cases heated waiting rooms. The effectiveness of such a campaign could be evaluated statistically if it were focused initially on a specific region.

With massive insulation from outdoor clothing, people in Yakutsk, the world's coldest city, already experience no excess winter mortality with midwinter temperatures that average around $-40^{\circ} \mathrm{C} .{ }^{5} \mathrm{It}$ is time for more balanced official action in Britain to reduce the exceptionally high mortality and recurrent hospital crises caused by Britain's mild winters.

William Keatinge professor

w.r.keatinge@qmw.ac.uk

Gavin Donaldson lecturer

Queen Mary School of Medicine and Dentistry,

Medical Sciences Building, Queen Mary and

Westfield College, London E1 4NS

1 Olsen NDL. Prescribing warmer, healthier homes. $B M$ 2001:322:748-49. (31 March.)

2 Rudge J, Nicol F. Cutting the cost of cold. London: $\mathrm{E}$ and N Spon, 2000

Eurowinter Group. Cold exposure and winter mortality from ischaemic heart disease, cerebrovascular disease, respiratory disease, and all causes in warm and cold regions of Europe. Lancet 1997;349:1341-6.

4 Keatinge WR. Seasonal mortality among people with unrestricted home heating. BMJ 1986;293:732-33.

5 Donaldson GC, Ermakov SP, Komarov YM, McDonald CP, Keatinge WR Cold related mortalities and protection from cold in Yakutsk, eastern Siberia BMJ 1998.317: $978-89$

\section{Lay members can contribute much in primary care groups}

EDITOR-Contrary to the findings of the King's Fund that lay members of primary care groups are finding it difficult to ensure that patients' views are heard, ${ }^{12}$ a study of lay members conducted by the University of Bristol indicates that they are increasingly confident in their ability to influence decision making.

In a postal survey of all primary care groups in the South West region (response rate $76 \%), 69 \%$ of lay members reported that they had either moderate or a lot of influence over decision making. They reported that their influence has increased with time as a result of their contribution to the work of the group and that they have gained credibility and earned the board's respect for their skills and experience. Their main contribution lies in fulfilling their responsibilities as a corporate board member, although many have taken the lead in public engagement.

The remaining $31 \%$ of lay members reported either limited or very limited influence; this was not associated with age, sex, prior knowledge of the NHS, or extent of previous board experience. Rather, isolation as the lone lay voice, lack of time, and general practitioners' dominance of the primary care group's agenda and decision making were reported as key constraints.

Such self reports can always be criticised as lacking objectivity, but they do reflect the level of confidence that lay members have in their ability to influence decisions, which is likely to be reflected in their participation in decision making.

The survey highlights that lay members have a dynamic and evolving role, their influence increasing with knowledge and experience and through successful interaction with other board members. Where lay members have been able to contribute their skills, this has caused other board members to revise their views on the benefits of lay participation, which in time may foster a culture that supports wider public involvement in the work of primary care groups and trusts.

Don't write lay members off too soon.

Rosemary Rowe postgraduate researcher School for Policy Studies, University of Bristol, Bristol BS8 1TZ

rosemaryrowe@earthlink.net

1 Richard T. Patients need a real say in the NHS, not just to be "muppets" says report. Abridged version: $B M$ be "muppets," says report. Abridged version: $B M$ J cgi/content/full/322/7289/754/b. (31 March.)

cgi/content/full/322/7289/754/b. (31 March.)
King's Fund. New beginnings: towards patient and public 2 King's Fund. New beginnings: towards patient and public don: Kings Fund, 2001

\section{Spirit of collaboration needs fostering}

EDITOR-Brassey et al in their paper describe the ATTRACT project in Wales, which received 193 queries from general practitioners in a period of 13 months. Many of these entailed therapeutics. But we regret Brassey et al's apparent lack of awareness of the United Kingdom Medicines Information service.

Medicines Information, formerly Drug Information, began in 1966. Most general hospitals in the United Kingdom have a centre, receiving enquiries from healthcare professionals in both primary and secondary care on all aspects of drug treatment. Centres are staffed by experienced pharmacists whose skills include linking information provision with clinical interpretation. These pharmacists use a variety of evidence based, critically assessed resources to provide the information needed to answer inquiries received. In 1997 these centres together answered more than 250000 inquiries (some 1000 per local centre), all of which were concerned with drug treatment. ${ }^{2}$ The network of centres provides a locally based and responsive service, with coordination at a national level. The chief pharmacists of the four home countries have recently acknowledged the expertise, impartiality, responsiveness, and efficiency of medicines information pharmacists through a national strategy which they have commended to healthcare providers. ${ }^{3}$

The coordination of medicines information services throughout the United Kingdom has facilitated many developments. We have established centres of national expertise with specialist knowledge in specific areas of therapeutics such as the use of drugs in pregnancy and complementary medicine. Nationally we conduct detailed reviews of drugs both before and after they are launched. We are also developing a comprehensive website.

There are nationally accepted standards for the provision of medicines information services, and individual centres are regularly audited externally against these. ${ }^{4}$ Those who use an information service and those who fund it need to be assured of its quality. Medicines information services can provide this assurance.

Our history has been one of collaboration and networking at all levels: Medicines Information works closely with the National Prescribing Centre, the National Institute for Clinical Excellence, and NHS Direct. Locally, we work with healthcare professionals from both primary and secondary care. Many interface prescribing committees, health authorities, primary care trusts, local health groups, and NHS librarians also benefit from a close liaison with their local medicines information pharmacist. Collaboration reduces duplication of effort and consequently makes more effective use of limited resources.

We would welcome the opportunity to share our experience with ATTRACT, and hope that this will foster a spirit of collaboration.

Fiona Woods director

Welsh Medicines Information Centre, University Hospital of Wales, Cardiff CF14 4XW fiona.woods@cardiffandvale.wales.nhs.uk

Peter Golightly director

Trent Regional Medicines Information Centre Leicester Royal Infirmary, Leicester LE1 5WW

Anne Lee principal pharmacist

Area Medicines Information Centre, Glasgow Roval Infirmary, 84 Castle Street, Glasgow G4 0SF

Simon Wills head

Wessex Drug and Medicines Information Centre, Mailpoint 40, Southampton General Hospital, Southampton SO16 6YD

1 Brassey J, Elwyn G, Price C, Kinnersley P. Just in time information for clinicians: a questionnaire evaluation of the ATTRACT project. BMJ 2001;322:529-30 (3 March.)

2 Hands D, Judd A, Golightly P, Grant E. Drug information and advisory services - past, present and future. Pharm J 1999:262:160-2

3 Better information for managing medicines: a strategy for pharmacy's Medicines Information Service in the NHS. UKM $i$ April 2000.

4 Golightly P, Grant E, McKee C, Simister K, Woods F. Made to measure. Health Service Journal 1994;104:22.

\section{Questionnaires for depression and anxiety}

\section{Systematic review is incomplete}

EDITOR-Gilbody et al published a systematic review of the effect in primary care settings of routinely administered questionnaires on the recognition, treatment, and outcome of psychiatric disorders, particularly depression. ${ }^{1}$ They reviewed randomised trials published throughout 2000 and concluded that the routine administration of such questionnaires is a costly exercise that has not been shown to influence clinicians' behaviour. 
On behalf of the United States Preventive Services Task Force, we performed a broader systematic review of the effectiveness of routine screening for depression. In addition to those reported in Gilbody et al, we identified six randomised trials of screening that examined recognition, treatment, or clinical outcomes. ${ }^{2-7}$ Each study used a validated screening instrument and gave feedback to providers of the screening results; some also confirmed results from the screening instrument with a criterion standard or gave systematic support to providers and patients to improve the quality of care after recognition of the diagnosis or condition. Gilbody et al cited the study by Wells et al in their discussion but did not include it in their analysis; other studies were not addressed in the report. Since several of these studies had positive impact on at least one major outcome, we are concerned that not including them may have affected the conclusions of the review. Gilbody et al included one study of depression screening that we did not identify. ${ }^{8}$ Even with the addition of the extra studies, we agree with Gilbody et al that interpreting the results of these screening trials is difficult because of the heterogeneity of outcome measures and times at which outcomes were assessed. In addition, because the minimal difference in outcome rates that is considered clinically important has not been defined, the question of whether existing trials have enough power to exclude an important effect remains unclear.

Gilbody et al surmise that because the post-test probability of major depression is only $50 \%$ after a positive screen, physicians may tire of sorting out actual cases from those who would not benefit clinically. We argue, by contrast, that a $35-50 \%$ probability of major depression is quite high enough to justify the next step-namely, a diagnostic interview lasting 10 minutes. Not acting on the results of a positive screen may be related to lack of familiarity with diagnostic interviewing, lack of skill in treating depression, or failure to appreciate the morbidity associated with depressive disorders. Systematic efforts to provide additional support for treatment and follow up, as employed in the study by Wells et al, may improve the likelihood of improved outcomes.

Michael Pignone assistant professor of medicine pignone@med.unc.edu

Bradley N Gaynes assistant professor of psychiatr Kathleen N Lohr professor of health policy and administration

University of North Carolina, Chapel Hill, NC 27599-7110, USA

C Tracy Orleans senior scientist Robert Wood Jones Foundation, Princeton, NJ 08543, USA

Cynthia Mulrow professor of medicine University of Texas Health Science CenterSan Antonio, San Antonio, TX 78284, USA

1 Gilbody SM, House AO, Sheldon TA. Routinely administered questionnaires for depression and anxiety. $B M J$ 2001;322:406-9. (17 February.)

2 Zung WW, King RE. Identification and treatment of masked depression in a general medical practice. J Clin Psychiatry 1983;44:365-8.

3 Callahan CM, Hendrie HC, Dittus RS, Brater DC, Hui SL, Tierney WM. Improving treatment of late life depression in primary care: a randomized clinical trial. J Am Geriatr Soc 1994;42:839-46

4 Reifler DR, Kessler HS, Bernhard EJ, Leon AC, Martin GJ Impact of screening for mental health concerns on health service utilization and functional status in primary care patients. Arch Intern Med 1996;156:2593-9.

5 Williams JW Jr, Mulrow CD, Kroenke K, Dhanda R, Badgett RG, Omori D, et al. Case-finding for depression in prmary care: a randomized trial. Am JMed 1999;106:36-43. 6 Wells KB, Sherbourne C, Schoenbaum M, Duan N, Meredith L, Unutzer J, et al. Impact of disseminating quality improvement programs for depression in managed primary care: a randomised controlled trial. JAMA primary care:

7 Whooley MA, Stone B, Soghikian K. Randomized trial of case-finding for depression in elderly primary car patients. J Gen Intern Med 2000;15:293-300.

8 German PS, Shapiro S, Skinner EA, Von Korff M, Klein LF Turner RW, et al. Detection and management of menta health problems of older patients by primary care providers. JAMA 1987;257:489-93.

\section{Routine screening entails additional pitfalls}

EDITOR-Gilbody et al, in their metaanalysis, challenge the conventional wisdom that routine screening is an efficient means of improving the outcome of depression in general medical settings. ${ }^{1}$ We agree that the allocation of resources that would be required to make such screening feasible is not warranted. It seems, however, that Gilbody et al could have made an even stronger case for their conclusions.

Specifically, they may have overestimated the efficiency of screening and underestimated the pitfalls inherent in its implementation. The positive predictive value of an elevated score on a screening instrument is typically less than $35 \%$, rather the $50 \%$ they assumed in analysis. ${ }^{2}$ Furthermore, the considerable professional resources consumed in resolving false positive cases decrease the resources available for efforts to improve the outcome of already detected patients. The PRIME-MD study showed this problem. More than $80 \%$ of the 1000 patients screened positive for a mental disorder, and most of these cases proved to be false positives. Clinicians averaged an additional eight minutes in their follow up interviews with these patients, an increase of over $50 \%$ in the length of a typical primary care visit. This effort, however, ultimately yielded only 16 new prescriptions for antidepressant medication. ${ }^{3}$ If implemented without significant (and costly) support, this programme would drastically reduce the time and resources available for follow up with previously identified patients. Another study recently showed how difficulties in obtaining patient acceptance and in integrating follow up interviews into the competing demands of biomedical care can substantially reduce the yield of new patients in need of treatment. ${ }^{4}$

Finally, there is the comparatively recent phenomenon, at least in North America, of the prevalence of antidepressant prescription equalling or exceeding the prevalence of depression among general medical patients. ${ }^{5}$ Some of this undoubtedly reflects increased detection of depressed patients and alternative uses for antidepressant drugs, but much of the increase represents inappropriate and inadequate treatment for depression.
This is especially important given repeated demonstrations that increased detection does not translate into improved outcomes in non-specialty settings. This situation is likely to be aggravated through the implementation of routine screening. Without efforts aimed at improving the outcome of already detected depression in routine general medical care and at reducing the inappropriate prescription of antidepressants, routine screening remains part of the problem, rather than the solution to untreated or inadequately treated depression outside of specialty mental health settings.

James C Coyne codirector, behavioural sciences and health services research

Jcoyne@mail.med.upenn.edu

Steven C Palmer chief postdoctoral fellow

Richard Thompson postdoctoral fellow, department of psychiatry

University of Pennsylvania, Comprehensive Cancer Center, 3400 Spruce Street/11 Gates, Philadelphia, PA 19104, USA

1 Gilbody SM, House AO, Sheldon TA. Routinely administered questionnaires for depression and anxiety. $B M$ 2001;322:406-9. (17 February.)

2 Coyne JC, Thompson R, Palmer SC, Kagee A, Maunsell E. Should we screen for depression? Caveats and pitfalls. Appl Should we screen for depression?
Preventive Psychol 2000;9:101-21.

3 Preventive Psychol 2000;9:101-21. Williams JBW, Spitzer RL, Linzer M, Kroenke K, Hahn SR,
DeGruy FV, et al. Gender differences in depression in primary care. Am J Obstet Gynecol 1995; 173:654-9.

4 Payne D, Hofman R, Theodoulou M, Dosik M, Massie M. Screening for anxiety and depression in women with breast cancer. Psychosomatics 1999;40:64-9.

5 Mamdani MM, Parikh SV, Austin PC, Upshur RE. Use of antidepressants among elderly subjects: Trends and contributing factors. Am J Psychiatry 2000;157:360-7.

\section{Two screening questions may be helpful}

EDITOR-In response to the systematic review by Gilbody et al on routine administered questionnaires for depression and anxiety, screening has not improved outcomes of patients with depression. ${ }^{12}$ Since that report there has been one study that asked patients a single question: "Have you felt depressed or sad much of the time in the past year?" The screened group were more likely to recover (48\% v 27\%, $\mathrm{P}<0.05$ ), presumably because those with major depression were more likely to be recognised $(45 \% v 24 \%)$ and treated $(55 \%$ v $28 \%, \mathrm{P}<0.02){ }^{3}$ Compared with the gold standard diagnostic interview schedule the single screening question had sensitivity of $85 \%$ of those with depression and a specificity of $66 \%$.

Another screening tool of two questions has been developed in a written form as opposed to an oral question. ${ }^{4}$ These two questions are, "During the past month have you often been bothered by feeling down, depressed or hopeless?" and, "During the past month have you often been bothered by little interest or pleasure in doing things?" A "yes" to either of these has a sensitivity and specificity of $96 \%$ and $66 \%$ for depression in patients in whom substance abuse is excluded. Written questionnaires are too time consuming for primary care physicians. The two screening question (consisting of two questions) is easy to remember and has a positive predictive value of $33 \%$ for a prevalence of depression of $15 \%$. Any patient with a positive response to either of these questions can be asked a few further questions from the Diagnostic and Statistical 
Manual of Mental Disorders, fourth edition, to rule depression in or out. This is a much more practical solution, and we are hoping to test these two questions in a clustered randomised controlled trial in general practice.

Bruce Arroll associate professor of general practice and primary health care

University of Auckland, Private Bag 92019,

Auckland, New Zealand

b.Arroll@auckland.ac.nz

1 Gilbody SM, House AO, Sheldon TA. Routinely administered questionnaires for depression and anxiety. $B M J$ tered questionnaires for dep

2 US Preventive Services Taskforce. Guide to clinical preventive services, second edition. Report of the US preventive services tash force (screening). Alexandria, Virginia: International Medical Publishing, 1996.

3 Williams JW, Mulrow CD, Kroenke K, Dhanda R, Badgett RG, Omori D, et al. Case-finding for depression in primary care: a randomized controlled trial. Am J Med 1999;106: $36-43$

4 Whooley MA, Avins AL, Miranda J, Browner WS. Case finding instruments for depression: two questions as good as many. J Gen Intern Med 1997;12:439-45.

\section{Exposure of healthcare workers to bloodborne viruses}

\section{Only the tip of the iceberg has been} measured

EDITOR-Evans et al try to measure the exposure of healthcare workers to bloodborne viruses by including incidents that are required to be reported under the 1995 regulations for reporting injuries, diseases, and dangerous occurrences. ${ }^{1}$ We do not, however, know the denominator-namely, the total number of needlestick injuries received by healthcare workers.

This denominator is an iceberg, the tip of which has been described by Evans et al. From the up to date surveillance data, which include additional information and extend to December 2000, hepatitis C is more common than HIV and hepatitis B combined in infected patients. A large London study

\section{Advice to authors}

We prefer to receive all responses electronically, sent directly to our website. Processing your letter will be delayed unless it arrives in an electronic form.

We are now posting all direct submissions to our website within 24 hours of receipt and our intention is to post all other electronic submissions there as well. All responses will be eligible for publication in the paper journal.

Responses should be under 400 words and relate to articles published in the preceding month. They should include $\leqslant 5$ references, in the Vancouver style, including one to the BMJ article to which they relate. We welcome illustrations.

Please supply each author's current appointment and full address, and a phone or fax number or email address for the corresponding author. We ask authors to declare any competing interest. Please send a stamped addressed envelope if you would like to know whether your letter has been accepted or rejected.

Letters will be edited and may be shortened.

bmj.com

letters@bmj.com showed, however, that most patients found to be infected with hepatitis $\mathrm{C}$ have not been previously identified by epidemiological risk factors. ${ }^{2}$ Therefore, by reporting on the injuries of patients known to be infected, the comparatively huge number of needlestick injuries in which hepatitis $\mathrm{C}$ positive patients are not known to be infected may be forgotten.

We have previously shown that surgeons report only one in 20 known needlestick injuries they receive. ${ }^{3}$ This is reflected in the paper's reported number of nurses' needlestick injuries-which is higher than that of doctors-and in the fact that over three times as many injuries are reported in wards as operating theatres. We should recognise that these reported figures do not scratch the surface of the actual number of occupational sharps injuries to healthcare workers.

Guy Nash research fellow

Hammersmith Hospital, London W12 0NN guy.nash@ic.ac.uk

1 Evans B, Duggan W, Baker J, Ramsay M, Abiteboul D. Exposure of healthcare workers in England, Wales and Northern Ireland to bloodborne viruses between Jul 1997 and June 2000: analysis of surveillance. $B M J$ 2001;322:397-8. (17 February.)

2 Ward C, Tudor-Williams G, Cotzias T, Hargreaves S, Regan L, Foster GR. Prevalence of hepatitis C among pregnan women attending an inner London obstetric department: uptake and acceptability of named antenatal testing. G 2000; $47: 277-80$.

3 Nash GF, Goon P. Current attitudes to surgical needlestick injuries. Ann R Coll Surg Engl 2000;82:236-7.

\section{Eye and face protection should be used}

EDITOR-Evans and et al, in the preliminary report of their ongoing epidemiological survey of risks to healthcare workers from bloodborne viruses, took the opportunity to reinforce the need for hepatitis B vaccination.

Given that almost a third of their reported exposures were mucocutaneous or splash exposures, they could also have taken the opportunity to raise awareness of the need for more general use of eye and face protection. It is still commonplace for this to be unavailable for use by staff, who may be exposed on a day to day basis to the risks of splash of high risk body fluids. Healthcare workers in the United Kingdom should follow the excellent example of those on the American television soap $E R$, where wearing of protective eyewear and masks is routine.

Nita Mitchell-Heggs consultant occupational physician

St George's Hospital, London SW17 OQT nita.mitchell-heggs@ccmail.stgh-tr.sthames.nhs.uk Competing interests: None declared.

I Evans B, Duggan W, Baker J, Ramsay M, Abiteboul D. Exposure of healthcare workers in England, Wales and Northern Ireland to bloodborne viruses between July 1997 and June 2000: analysis of surveillance. BM] 2001;322:397-8. (17 February.)

\section{NHS staff must be trained in how to prevent aggression}

EDITOR-"I suddenly cut across three lanes of traffic without signalling and made an abusive gesture at anyone who sounded their horn." It is hardly surprising, even though it is unacceptable, if a psychopath gets out of his car and punches that driver. The driver then claims to be an innocent victim of road rage. Not many victims of violence admit to that sort of behaviour, and they wouldn't get much sympathy if they did. NHS staff receive physical and verbal abuse from patients and relatives for three reasons.

Firstly, by the nature of our work we deal with people who may be frightened or anxious, or feel guilty or angry. Everyone gets angry sometimes, some more often and more easily than others. Some quickly become violent, which can never be acceptable. Secondly, we receive abuse because of the system we work in-not enough time, too many patients to see, not enough resources to meet the demand, working long hours. It is easy to blame the system, but how often do staff accept the third reason-that victims may instigate the aggression because of their behaviour? All readers have experienced behaviour by employees in public services (including the NHS) and the private sector that is rude, facetious, insulting, bullying, or provocative. If we are honest we have probably all been guilty of that at some time.

It is easy to imagine that people with poor self restraint or a low threshold for violence would quickly become aggressive when treated like that. MacDonald highlights the issue of violence against health service staff and the NHS zero tolerance campaign, and she gives recommendations for the aftermath of verbal or physical violence.

Training programmes are available that discuss ways of staying safe on home visits, and how to diffuse anger when someone has become angry and aggressive. These include letting colleagues know your whereabouts and timetable and, in a potentially threatening situation, what to do and say, and what body language to adopt. Treating people with respect and courtesy and being assertive are not mentioned in personal safety seminars.

This is not blaming the victims, and physical and verbal violence towards staff cannot be tolerated or excused. But NHS staff need to recognise, preferably before they become victims, that their words or manner can prevent or induce aggression and confrontation.

Charles Essex consultant neurodevelopmental paediatrician

Child Development Unit, Gulson Hospital,

Coventry CV1 2HR

room101@ntlworld.com 1 MacDonald R. Violence against NHS staff [career focus].
BMJ 2001;322(classified section 31 March):1-2. (www.bmj.com/cgi/content/full/322/7289/S2-7289)

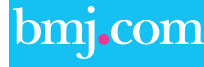

\section{Rapid responses}

Correspondence submitted electronically

is available on our website 